Review began 02/08/2022 Review ended 02/14/2022 Published 02/20/2022

\section{(c) Copyright 2022}

Lesi et al. This is an open access article distributed under the terms of the Creative Commons Attribution License CC-BY 4.0. which permits unrestricted use, distribution, and reproduction in any medium, provided the original author and source are credited.

\title{
Thyroid Hemiagenesis: Narrative Review and Clinical Implications
}

Omotara Kafayat Lesi ${ }^{1}$, Ankur Thapar ${ }^{2}$, Nikhil Nanjappa Ballanamada Appaiah ${ }^{3}$, Muhammad Rafaih Iqbal ${ }^{3}$, Shashi Kumar ${ }^{3}$, Dale Maharaj ${ }^{4}$, Abdalla Saad Abdalla Al-Zawi ${ }^{5,}$ 6, 7 , Shiva Dindyal ${ }^{2}$

1. General and Colorectal Surgery, Basildon and Thurrock University Hospitals, Mid and South Essex NHS Foundation Trust, Essex, GBR 2. Vascular Surgery, Basildon and Thurrock University Hospitals, Mid and South Essex NHS Foundation Trust, Essex, GBR 3. Colorectal Surgery, Basildon and Thurrock University Hospitals, Mid and South Essex NHS Foundation Trust, Essex, GBR 4. Vascular Surgery, Caribbean Vascular \& Vein Clinic, Port-of-Spain, TTO 5. General and Breast Surgery, Mid and South Essex University Hospital Group, Basildon, GBR 6. General and Breast Surgery, Basildon and Thurrock University Hospitals, Mid and South Essex NHS Foundation Trust, Essex, GBR 7. General and Breast Surgery, Anglia Ruskin University, Chelmsford, GBR

Corresponding author: Omotara Kafayat Lesi, omotaralesi@gmail.com

\section{Abstract}

Thyroid Hemiagenesis (THA) is an uncommon, congenital anomaly defined by the absence of one thyroid lobe with or without the isthmus. Reports suggest it may be found more often in regions endemic for hypothyroidism. Genetic abnormalities are thought to have a role based on findings in monozygotic twins. Most cases are sporadic, however familiar clusters have also been documented. It is found more frequently in females. A majority of patients report no symptoms and THA is found incidentally during investigations or intraoperatively. THA is usually associated with normal thyroid function, but it can present with thyroid hypofunction.

Since a majority of patients are asymptomatic, there are no specific recommendations for management. Ultrasound imaging and thyroid scintigraphy using technetium or iodine are useful in diagnosis. Its clinical importance occurs when the remnant thyroid lobe requires excision leading to the lifelong requirement for thyroxine supplementation.

Published English literature (Medline, PubMed, and Embase databases) was searched. Medical subject headings (MeSH) terms used were "thyroid hemiagenesis," "one thyroid lobe," and "thyroid aplasia”. Case reports, case series, and original articles were selected to provide a framework for this review.

Articles reviewed were published in the past 20 years. The association of THA with thyroid cancer was explored. In this group, the F:M ratio was 3.25:1. Left THA constituted 53\% of cases, right THA in 29.4\%, and isthmus absence in $17.6 \%$ of cases. Also, the authors investigated the link between THA and hyperparathyroidism, both left and right THA are seen in an equal number of cases in the hyperparathyroidism subgroup. In patients with THA and Grave's disease, left THA was seen in a majority of cases (86.7\%), while an equal number of left and right THA was observed in patients with Hashimoto's thyroiditis. In addition, congenital abnormalities associated with THA were observed, the left THA was seen in $60 \%$ and right THA in $40 \%$ of cases of this subgroup.

The summative review provided a detailed insight into the epidemiology, aetiopathogenesis, genetics, symptomatology, diagnosis, and treatment for THA by combining findings and results from almost a hundred research papers from around the world. THA remains a poorly understood, often incidentally detected, abnormality in euthyroid patients undergoing investigations and treatment for other thyroid disorders.

Categories: Endocrinology/Diabetes/Metabolism, Anatomy

Keywords: thyroid dysgenesis, one lobe thyroid, thyroid cancers, thyroid hemiagenesis, thyroid aplasia

\section{Introduction And Background}

Thyroid Hemiagenesis (THA) is an uncommon, congenital anomaly defined by the absence of one thyroid lobe with or without the isthmus [1]. The origin of thyroid gland development starts from the medial thyroid anlage derived from the primitive pharynx while the lateral thyroid anlage is derived from neural multipotent cells. Anomalies in their development can lead to abnormalities in the structure or function of which THA is a part [2]. Genetic abnormalities may have a role to play in the etiology of THA as reported in monozygotic twins [3]. Different studies have shown that in $80 \%$ of cases, it affects the left lobe with an L:R ratio of $4: 1$. The absence of the isthmus is seen in $50 \%$ of cases with hemiagenesis of the left lobe while the absence of the right lobe is seen mostly with agenesis of the isthmus [4]. Frequently, THA is an incidental phenomenon as the majority of patients have normal thyroid function. They are discovered during surgery (Figure 1) or diagnostic imaging for other head and neck pathologies [1]. The true prevalence of this 


\section{Cureus}

anomaly is therefore uncertain because most patients remain asymptomatic and therefore presumably undiagnosed [5]. There is no specific recommendation for management, especially in asymptomatic cases and its clinical importance occurs when the remnant thyroid lobe requires excision leading to the lifelong requirement for thyroxine supplementation $[4,6]$.

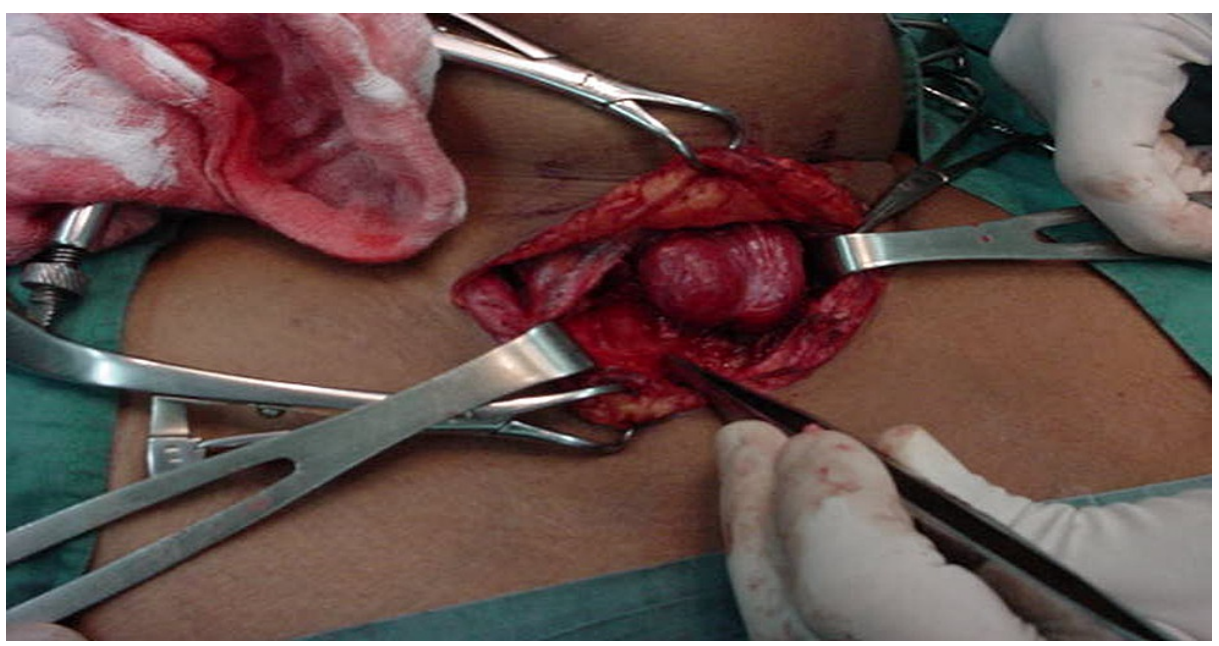

\section{FIGURE 1: Patient with thyroid hemiagenesis undergoing surgery}

This image is a property of the Department of Surgery, University of the West Indies, General Hospital, Port-ofSpain, Trinidad, West Indies

\section{Review}

\section{Epidemiology}

Handfield-Jones published the first case of THA in the "Cyclopaedia of Anatomy and Physiology" by Robert B. Todd in 1852 [7], also Luschka reported about the pathology in 1876 followed by Ehlers in 1886 [8]. The true prevalence is unknown but is estimated to be between $0.02-0.2 \%$ [9], and slightly increased prevalence was reported in an endemic area where there was a high incidence of goiter and thyroid nodules [10]. Children with congenital hypothyroidism have been reported to have a higher prevalence up to $3.7 \%$ [11,12]. A study of asymptomatic school children in Northern Poland between the ages of 7-15 years revealed a prevalence of $0.05 \%$. This prevalence was also similar to the study of 11 to 14 -year-old schoolchildren in Sicily which revealed a prevalence of $0.05 \%$ [5], while Shabana et al. in Belgium revealed a prevalence of $0.2 \%$ in asymptomatic school children [13]. Another paper by Gursoy et al. revealed a prevalence of $0.25 \%$ in patients with various thyroid disorders [14].

THA is more common in females, however, this could reflect that thyroid diseases are more frequent in females $[13,15,16]$. A large cohort study of 40 patients by Ruchala et al. revealed a considerable prevalence of women with a Female:Male ratio of 7:1 [17]. A study by Mikosch et al. also revealed a prevalence of 4.3:1 in the 16 patients with THA out of 71,500 patients who had thyroid investigations in 9 years [16].

The most common feature is the absence of the left lobe (missing in $80 \%$ of patients) [18]. This set of patients has a greater incidence of associated functional, morphological and autoimmune thyroid disorders such as Hashimoto's thyroiditis, Graves' disease in addition to simple and nodular toxic goiter [10]. The presence or absence of the isthmus is not fixed as it is seen in 50\% of cases, with a distinctive hockey-stick sign on scintigraphy [19]. A study by Suzuki et al. in Fukushima, Japan to determine the prevalence of THA revealed a statistically significant presence of left hemiagenesis in 55 patients compared to 12 patients with right THA [20].

\section{Embryology of thyroid gland}

The thyroid gland development spans from the third week of gestation to the eleventh week of gestation [21]. It arises from a medial anlage which is larger and a paired smaller lateral anlage [22]. The origin of the median anlage is marked by a permanent pit at the apex of the sulcus terminalis on the dorsum of the tongue known as the foramen cecum. This medial primordium starts from the 3rd week as a proliferation/thickening of the endodermal epithelial cells in the floor of the pharynx inferior to the tuberculum impar (ventral pharyngeal wall) at the border of the first and second pharyngeal pouches. It appears as a duct-like invagination of the endoderm in the floor of the pharynx. This midline structure undergoes numerous transformations like enlargement, bifurcation, lobulations, and detachment from the pharynx [21]. The thyroid gland is initially spherical and then assumes a more bilobed structure as it enlarges [23]. Also, the 
structure which is initially hollow later solidifies forming follicular elements of the thyroid gland. Division of the gland into lateral lobes, if not present from the beginning, takes place so early that it is impossible to establish whether the thyroid gland arises as a single unit or as a paired organ [24].

During its migration, it descends in front of the hyoid bone and laryngeal cartilages and then settles in its final position anterior to the trachea by the end of the 7th week of gestation [21]. The gland is connected to the foramen cecum by the thyroglossal duct during the migration. The duct later disappears and may remain as a strip of fibrous tissue. The two lobes are located on either side of the midline and connected via an isthmus [24].

The lateral thyroid primordia arise from the ventral part of the 4th and 5th pharyngeal pouches in the ultimobranchial bodies and become attached to the posterior part of the thyroid during the 5th week. It provides $30 \%$ of the weight of the thyroid gland [22]. The lateral primordia originate from the neural crest cells (ultimobranchial bodies) and provide the parafollicular $\mathrm{C}$ cells which produce calcitonin. At the end of the 7th week, the thyroid gland has a median isthmus and two lateral lobes.

The thyroid follicular cells develop from the median thyroid anlage, begin to appear by the 8th week of gestation and most are formed by the 16th week of gestation. By the end of the 12th week, follicles containing colloid become apparent and begin to incorporate radioactive iodine. Thyroid hormone is produced and secreted into the circulatory system as early as the 10 th to 12 th week of intra-uterine life [21].

Congenital anomalies during descent (i.e. the presence of thyroglossal cysts) are more common compared to the absence of either lobe which is quite rare [25]. The cause of THA is not known and possible theories include failure of descent, defects in lobulation, or genetic aberrations [4].

\section{Molecular patterns for THA}

Transcription factors such as NKX2-1, PAX8, FOXE1, NKX2-5, TSHR have been shown to contribute to the increase and movement of thyroid precursor cells during embryogenesis but mutation in the genes having a role in thyroid morphogenesis has only been reported in a few patients [26]. Most cases are sporadic, however, familiar clusters have also been documented [27].

The FOXE1 gene is seen on the long arm of chromosome 9 at position 22. It is expressed in the thyroid gland, tongue, palate, choane, and hair follicles. It acts as a thyroid transcription factor and plays a critical function in the development of the thyroid gland. Moreover, it controls the transcription of thyroglobulin and thyroid peroxidase genes. Within the FOXE1 gene is a coding sequence of polyalanine tract (FOXE1-polyAla) of variable length ranging from 11 to 19 alanines. Szczepanek et al. did a study in 2011 of 40 patients with THA which included 6 familial cases and a control group of 89 patients with normal thyroid glands. The study revealed a short variant of FOXE1-polyAla containing 12 alanines seen in five control patients but was not found in THA patients. The incidence of longer variants $>16$ codons of FOXE1-polyAla was seen to be significantly higher in patients with the familial form of THA when compared to those with sporadic or the control patients. They concluded that FOXE1-polyAla tract expansion may contribute to the molecular background of familial but not sporadic forms of THA [27].

There has been documentation of heterozygous mutation in Paired box gene 8 ( $P A X 8$ gene) as a cause. PAX 8 gene is located on the long arm of chromosomes 12 to 14 . It is a part of the paired box family of transcription factors involved in controlling the optimal development of the thyroid gland, Mullerian tracts as well as upper urinary tracts. Macchia et al. reported mutations in PAX8 with a reduction in the DNAbinding activity of the gene in two sporadic cases and one familial case of thyroid dysgenesis. The first sporadic patient had thyroid ectopy with reduced thyroid gland while the second sporadic case had thyroid hypoplasia. The familial cases had thyroid hypoplasia as well. The study revealed a $100 \%$ concordance between $P A X 8$ mutations and thyroid dysgenesis suggesting that $P A X 8$ gene plays an important role in the proliferation or survival of differentiated thyroid cell populations [28]. Mutations of $P A X 8$ gene was also reported in four generations of Jewish-Hungarian family with varying thyroid abnormalities including THA [29].

Szczepanek-Parulska et al., 2021, showed an association of THA phenotype and the presence of compound heterozygous mutations of GLI3 gene in two siblings with left THA [30]. The GLI3 gene is located on the $7 \mathrm{p} 14.1$ chromosome. It encodes a cytoplasmic protein that plays a vital part in the development which activates patched Drosophila homolog gene expression. This gene is expressed in various organs including ovaries, placenta, endometrium, and the thyroid gland. The GLI3 protein is a transcription factor and negative regulator of sonic hedgehog (shh) signaling, governing the symmetric lobulation of the thyroid gland. Both sisters had compound heterozygous mutations in the GLI3 gene affecting exon 14 and 15 . These mutations were also present in the daughters of the affected patients but all examined offspring had normal ultrasounds of bi-lobed thyroid gland thus inferring the presence of an autosomal recessive transmission in the GLI3 gene [30].

THA has been shown to not only be involved with mutations in genes directly involved in thyroid 
development but also mutations in conservative proteasome genes. In 2017, Budny et al's study showed 31 of 34 sporadic patients diagnosed with THA and one three-generation family revealed the presence of four recurrent defects (three deletions and one duplication) affecting proteasome genes PSMA1, PSMA3, and PSMD3 as well as a splice site mutation in a proteasome gene PSMD2 [31]. Dysfunction of the proteasomalubiquitin system has been researched in cardiac diseases and it's known that the development of the thyroid gland is indispensably linked to the cardiovascular system due to the proximity of the thyroid bud to the cardiogenic mesoderm and supported by the presence of heart defects in patients with congenital hypothyroidism $[32,33]$.

\section{Diagnosis/investigation of choice}

Ultrasound scan is the first imaging modality of choice as it is sensitive in detecting the absence of the lobe as well as any structural changes to the remaining lobes [11,16,34-36]. It is also widely available, cheap with no risk of radiation to patients. However, it is operator-dependent. Mikosch et al. studied the use of ultrasonography as it was the key investigative tool in diagnosing 16 patients with THA out of 71,500 patients in 9 years [16].

Following ultrasound, thyroid scintigraphy using technetium or iodine detects the functional anatomy of the thyroid gland with the added advantage of being able to detect the presence of hyperactivity and increased diffuse uptake in the glands [36]. Furthermore, scintigraphy can be used to detect ectopic thyroid tissue as well as diagnose thyroid pathologies in the remaining lobe associated with hyperthyroidism or a nodule suspicious of cancer [3]. The disadvantage of scintigraphy is due to artifacts related to the inability to view a thyroid lobe due to cancer, a contralateral autonomous solitary thyroid nodule suppressing normal tissue function, inflammatory and infiltrative pathologies of the thyroid gland, also the use of computed tomography scans have been helpful in further establishing the diagnosis.

\section{Hormonal status with THA}

THA is usually associated with normal thyroid function and clinically euthyroid patients with normal levels of thyroxine(T4), triiodothyronine(T3), and thyroid-stimulating hormones (TSH). However, some studies have shown deranged thyroid function tests in patients with THA. Increased TSH levels serve as a growth stimulus for the remaining thyroid lobe leading to hypertrophy i.e., either a diffuse or nodular goitre with an increase in the probability of becoming cancerous [37]. Ruchala et al.'s cohort study of 40 patients with THA reported having higher TSH and FT3 levels when compared to people with the presence of both thyroid lobes. This could be as a result of enhanced peripheral conversion of $\mathrm{T} 4$ to $\mathrm{T} 3 \mathrm{or}$ stimulated thyroidal $\mathrm{T} 3$ secretion due to elevated TSH in response to thyroid hormones insufficiency. Also, the elevated TSH could result in constant thyroid overstimulation and hypertrophy of the remaining parenchyma lobe [17]. Maiorana et al.'s study of school children in Sicily also revealed similar findings with significantly increased levels of TSH and FT3 in those with THA [5].

Szczepanek-Parulska et al. in 2016, performed a large cohort study of sixty-five patients with THA and revealed a high prevalence of elevated thyroid auto-antibodies with patients having more clinical manifestation of thyroid autoimmune pathology [38]. This could be attributed to a hypothesis in which excessive stimulation of TSH receptors may lead to the "leak" of some thyroid autoantigens such as thyroglobulin or thyroid peroxidase into the circulation leading to an autoimmune response and resultant autoantibody thyroid development [39].

Gurleyik and Gurleyik's study, 2015, published two case reports of patients with left THA and features of thyrotoxicosis with both cases being from a region of endemic goiter with a history of decreased consumption of iodine in diet [36]. Both patients had suppressed TSH levels with increased free thyroxine (T4) and free triiodothyronine (T3) levels with the second patient having raised antithyroid peroxidase and thyrotropin receptor antibodies with a diagnosis of toxic multinodular goitre and Graves's disease respectively. Both were initially treated with anti-thyroid medications before having thyroidectomies. Kocakusak et al. in 2004 described a female patient with left THA and absent isthmus with features of hyperthyroidism treated with anti-thyroid medications and surgery [40]. Mortimer et al. in 1981 described four patients with thyrotoxicosis with associated THA. The presence of THA also was identified during thyroid scintigraphy and confirmed during surgical exploration or post-mortem examination [41].

\section{Co-existing thyroidal and extra-thyroidal pathologies}

THA can be found in association with clinical pathologies such as nodules, de Quervain thyroiditis, hyperthyroidism [36], thyroid adenomas, Graves'disease [42], or Hashimoto's thyroiditis [43]; furthermore, THA can interestingly be associated with hyperparathyroidism. Anatomic abnormalities with THA include the absence of an isthmus, the presence of a thyroglossal cyst, a sublingual ectopic thyroid, cervical thymic cysts [44], absence of the thyroid superior and inferior thyroid vessels, and superior or recurrent laryngeal nerves ipsilateral to the missing lobe as well as the loss of the parathyroid gland.

The recent reports showed that thyroid cancer is the fifth most common malignancy diagnosed in women after breast, colorectal, lung, and uterine cancers [45-47]. Studies have shown the association of THA with 


\section{Cureus}

thyroid cancers. There were twenty-three cases reviewed in this paper (Table 1). The studies were done between 1970 and 2021. The F:M ratio was 4.75:1 with an age range between 14-74 years. Left THA comprised $52 \%$ of cases seen, right THA was seen in $34.8 \%$ of cases, and absence of the isthmus was seen in $13 \%$ of the cases. In twenty patients with true THA, the isthmus was present in nine patients, absent in four patients, and not documented in seven patients. Papillary thyroid cancer was the most common cancer seen as it was documented in $91 \%$ of patients. This is also the most common type of thyroid cancer worldwide.

\begin{tabular}{|c|c|c|c|c|c|c|c|}
\hline Study & $\begin{array}{l}\text { Patients } \\
\text { (n) }\end{array}$ & Gender & Age & $\begin{array}{l}\text { Thyroid } \\
\text { Hemiagenesis }\end{array}$ & Isthmus & $\begin{array}{l}\text { Nodule } \\
\text { Tomography }\end{array}$ & $\begin{array}{l}\text { Thyroid } \\
\text { Tumour }\end{array}$ \\
\hline Huang et al., 2002 & 1 & Female & 47 & Right & Present & Left lobe & PTC \\
\hline Pizzini et al., 2005 & 1 & Male & 54 & Left & Present & Right lobe & PTC \\
\hline Ammaturo et al., 2007 & 1 & Female & 39 & Left & ND & Right lobe & PTC \\
\hline Canani et al., 2008 & 1 & Female & 35 & Right & ND & Thyoglossal duct & PTC \\
\hline Lee et al., 2008 & 1 & Female & 69 & Left & ND & Right lobe & PTC \\
\hline Karatağ et al., 2013 & 1 & Female & 59 & Left & Present & Right lobe & PTC \\
\hline Vayisoglu et al., 2013 & 1 & Female & 43 & Isthmus & - & Right lobe & PTC \\
\hline Wang J et al., 2014 & 2 & Females & $49(60)$ & Right(Left) & - & Left lobe(Right lobe) & MTC (PTC) \\
\hline Campenni et al., 2015 & 1 & Male & 36 & Left & ND & Right lobe & PTC \\
\hline Sakorafas et al., 2015 & 1 & Female & 47 & Left & ND & Right lobe & PTC \\
\hline $\begin{array}{l}\text { Rajbhandari et al., } \\
2016\end{array}$ & 1 & Male & 28 & Isthmus & - & Right lobe & PTC \\
\hline Sato et al., 2017 & 1 & Female & 64 & Left & ND & Absent tissue* & PTC +PDC \\
\hline Ugur et al., 2019 & 1 & Female & 54 & Isthmus & - & Both lobes & PTC \\
\hline Gandla et al., 2020 & 1 & Female & 20 & Right & Present & Left lobe & FV of PTC \\
\hline Alqahtani et al., 2021 & 2 & $\begin{array}{l}\text { Female } \\
\text { (Male) }\end{array}$ & $36(40)$ & Right(Left) & Present & Left lobe(Right lobe) & PTMC (PTC) \\
\hline
\end{tabular}

\section{TABLE 1: Summary of case reports of THA in association with thyroid cancer}

PTC- Papillary Thyroid Cancer; FTC-Follicular Thyroid Cancer; MTC-Medullary Thyroid Cancer; PTMC: Papillary Thyroid Microcarcinoma; PDC: Poorly Differentiated Carcinoma; FV: Follicular variant; ND-Not detected.

*Adjacent to the absent left tissue; **Poorly differentiated carcinoma *** Oncocytic variant of papillary thyroid cancer (OVPTC)

Huang et al., 2002 [48]; Pizzini et al., 2005 [49]; Ammaturo et al., 2007 [50]; Canani et al., 2008 [51]; Lee et al., 2008 [52]; Karatağ et al., 2013 [53]; Vayisoglu et al., 2013 [54]; Wang et al., 2014 [55]; Campenni et al., 2015 [26]; Sakorafas et al., 2015 [56]; Rajbhandari et al., 2016 [57]; Sato et al., 2017 [9]; Ugur et al., 2019 [58]; Gandla et al., 2020 [59]; Alqahtani et al., 2021 [60]

The first article describing the association of THA with parathyroid adenoma was by Maganini and Narendran in 1977 [61]. This was seen in a 37-year-old man with left THA and left inferior parathyroid adenoma. A total of 11 cases were reviewed in this current study (Table 2). In six of the 11 reviews, the parathyroid adenoma was present on the ipsilateral side of the THA (five on the left and one on the right). Four of the parathyroid adenomas were located contralateral to the THA while the remaining study had the adenomas located in both left and right parathyroid glands. Of the six ipsilateral cases, three of the adenomas developed from the inferior gland, two from the superior gland while the last one was from both superior and inferior glands. 


\section{Cureus}

\begin{tabular}{|c|c|c|c|c|c|c|c|}
\hline Study & Gender & Age & $\begin{array}{l}\text { Thyroid } \\
\text { Hemiagenesis }\end{array}$ & Site of PA & $\begin{array}{l}\text { THA with } \\
\text { PA }\end{array}$ & $\begin{array}{l}\text { Size of PA after } \\
\text { surgery }\end{array}$ & Isthmus \\
\hline Sakurai et al., 2007 & Male & 42 & Right & Left inferior & Contralateral & $15 \times 10 \times 10 \mathrm{~mm} 600 \mathrm{mg}$ & Present \\
\hline Mydlarz et al., 2010 & Female & 55 & Left & Left upper and inferior & Ipsilateral & 2.2 and $2.4 \mathrm{~cm}$ & ND \\
\hline Isreb et al., 2010 & Female & 75 & Left and Isthmus & Left inferior & Ipsilateral & ND & Absent \\
\hline Kroeker et al., 2011 & Male & 41 & Left & Left inferior & Ipsilateral & $1.308 \mathrm{gms}$ & ND \\
\hline Oruci et al., 2012 & Female & 66 & Right & $\begin{array}{l}\text { Left Inferior, right } \\
\text { upper }\end{array}$ & Bilateral & $8 \times 6 \mathrm{~mm}, 15 \times 8 \mathrm{~mm}$ & Present \\
\hline Ferrari et al., 2014 & Female & 15 & Left & Right Inferior & $\begin{array}{l}\text { Contra } \\
\text { lateral }\end{array}$ & $11 \times 5 \times 4 \mathrm{~mm}$ & Present \\
\hline Eroglu et al., 2015 & Female & 27 & Right & Right & Ipsilateral & $20 \times 11 \mathrm{~mm}$ & ND \\
\hline $\begin{array}{l}\text { Alqahtani et al., } \\
2021\end{array}$ & Female & 36 & Right & Left inferior & Contralateral & $3.5 \times 2.5 \times 1.5 \mathrm{~cm}$ & Present \\
\hline
\end{tabular}

\section{TABLE 2: Summary of case reports of THA with primary hyperparathyroidism}

ND: Not detected.

Sakurai et al., 2007 [62]; Mydlarz et al., 2010 [63]; Isreb et al., 2010 [64]; Kroeker et al., 2011 [65]; Oruci et al., 2012 [66]; Ferrari et al., 2014 [2]; Eroglu et al., 2015 [67]; Alqahtani et al., 2021 [60]

The occurrence of Graves' disease (GD) with THA is uncommon and Table 3 shows a list of the majority of published case reports to date. The clinical features seen with GD are similar to other types of thyrotoxicosis but there is the presence of extrathyroidal features unique to GD including orbital disease, skin and nail changes with about 30-50\% of patients having obvious orbitopathy. In the list of case reports, a case of T3 thyrotoxicosis associated with THA was reported in 1982 [68]. In following years, two cases of THA developing GD after hypothyroidism [69,70], one familial form of thyroid dysgenesis [71], one nodular variant GD developing spontaneous hypothyroidism after following medical treatment [72], one case of Down syndrome developing GD following hypothyroidism [73], one multinodular goiter [74] and one hypercalcemia associated with GD [75] were seen. The first reported case of THA and GD in the UK was by Faulkner et al. in 2019. The patient was a 31-year-old female with left THA and GD who subsequently had right hemithyroidectomy and isthmusectomy [25]. 


\section{Cureus}

\begin{tabular}{|c|c|c|c|c|}
\hline Studies & Patients (n) & Gender & Age & Thyroid Hemiagenesis \\
\hline Veliz and Pineda, 2000 & 1 & Female & 35 & Left \\
\hline Hervas Benito et al., 2001 & 1 & Male & 45 & Right \\
\hline Zangeneh et al., 2001 & 1 & Female & 31 & Left \\
\hline Lee et al., 2003 & 1 & Female & 44 & Left \\
\hline Ozgen et al., 2004 & 1 & Female & 29 & Left \\
\hline Baldini et al., 2005 & 1 & Female & 41 & Left \\
\hline Ruchala et al., 2008 & 1 & Female & 49,51 & Left \\
\hline Nebesio and Eugster, 2009 & 1 & Female & 10 & Left \\
\hline Kebapcilar et al., 2009 & 1 & Female & 43 & Left \\
\hline Serdengecti et al., 2009 & 1 & Female & 8 & Left \\
\hline Cakir et al., 2009 & 1 & Female & 55 & Left \\
\hline Berker et al., 2010 & 1 & Male & 63 & Left \\
\hline Philip et al., 2014 & 1 & Female & 50 & Right \\
\hline Cansu et al., 2017 & 1 & Female & 45 & Left \\
\hline Faulkner et al., 2019 & 1 & Female & 31 & Left \\
\hline
\end{tabular}

\section{TABLE 3: Summary of case reports of THA with Graves Disease}

THA: Thyroid hemiagenesis.

Veliz and Pineda, 2000 [78]; Hervas Benito et al., 2001 [79]; Zangeneh et al., 2001 [80]; Lee et al., 2003 [52]; Ozgen et al., 2004 [81]; Baldini et al., 2005 [72]; Ruchala et al., 2008 [70]; Nebesio and Eugster, 2009 [73]; Kebapcilar et al., 2009 [75]; Serdengecti et al., 2009 [82]; Cakir et al., 2009 [74]; Berker et al., 2010 [35]; Philip et al., 2014 [83]; Cansu et al., 2017 [84]; Faulkner et al., 2019 [25]

TSH stimulation test and scintiscan with Tc-99 or Iodine had been used until the 1990s for differential diagnosis of GD and THA. Thyroid autoantibodies were used afterward and the TSH stimulation test was abandoned. Schechner et al. indicated thyroid-stimulating immunoglobulin (TSI) was more efficacious for distinguishing GD from toxic adenoma and the TSH stimulation test was obsolete in 1992 [76].

Thyrotropin receptor antibody (TRAb) measurement was first reported in a case report in 1994 [77].

Table 4 outlines a summary of case reports of THA with features of Hashimoto's thyroiditis (HT) in which histology confirmation revealed chronic lymphocytic thyroiditis. A total of nine case reports were reviewed. All patients were females confirming the increased incidence in women with the majority of the THA occurring in the left lobe. A few of the cases had a conversion from HT to hyperthyroidism after treatment with thyroxine while another few were diagnosed with HT after initial treatment for hyperthyroidism with anti-thyroid medications. Finally, Table 5 highlights the congenital anomalies that have been documented with THA as a dysmorphic face with short stature and Down's Syndrome. 


\section{Cureus}

\begin{tabular}{|c|c|c|c|c|c|}
\hline Study & Patients (n) & Gender & Age & Thyroid Hemiagenesis & Isthmus \\
\hline Sharma et al., 2001 & 1 & Female & 33 & Left & Present \\
\hline Ruchala et al., 2008 & 1 & Female & 49 & Left & ND \\
\hline Nsame et al., 2013 & 1 & Female & 23 & Right & Absent \\
\hline Wang et al., 2017 & 1 & Female & 31 & Left lobe and left PTG & ND \\
\hline Bosco et al., 2017 & 1 & Female & 50 & Left & Absent \\
\hline
\end{tabular}

TABLE 4: Summary of case reports of THA with Hashimoto's thyroiditis

THA: Thyroid hemiagenesis; ND: Not detected.

Sharma et al., 2001 [85]; Ruchala et al., 2008 [70]; Nsame et al., 2013 [86]; Wang et al., 2017 [43]; Bosco et al., 2017 [87]

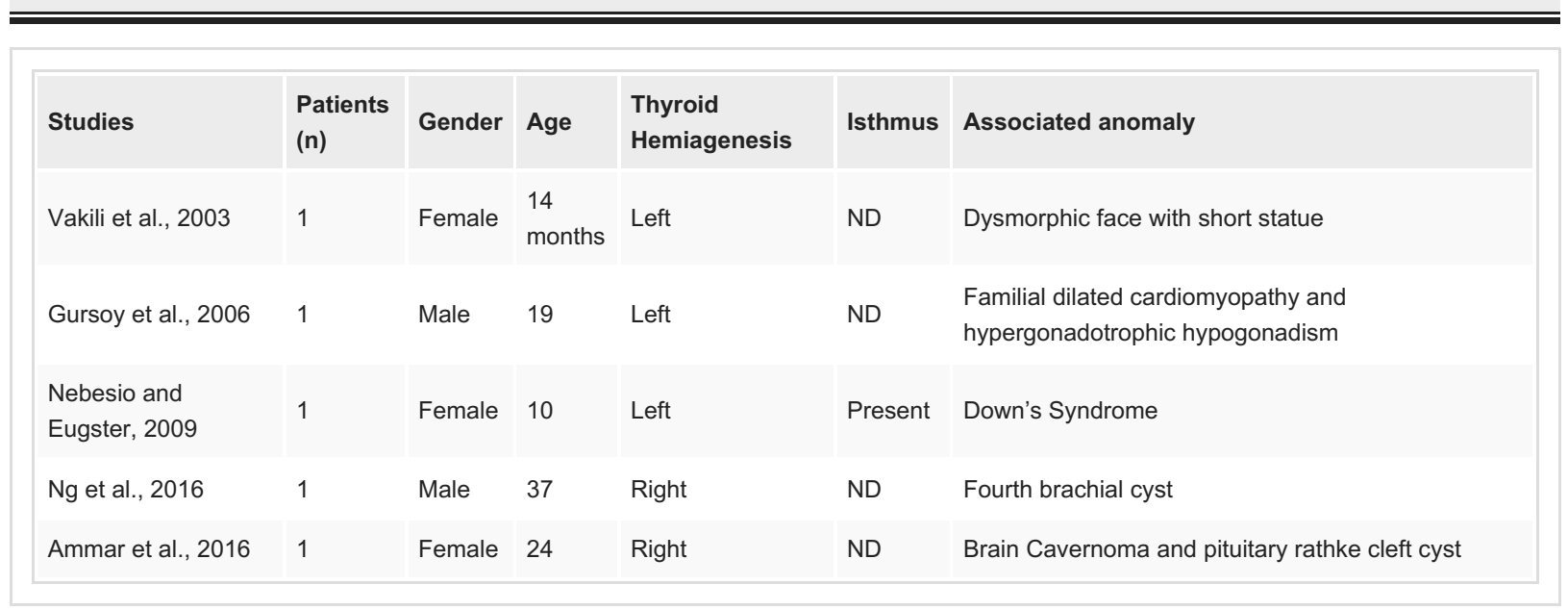

TABLE 5: Summary of case reports of congenital anomalies with THA

THA: Thyroid hemiagenesis; ND: Not detected.

Vakili et al., 2003 [88]; Gursoy et al., 2006 [89]; Nebesio and Eugster, 2009 [73]; Ng et al., 2016 [90]; Ammar et al., 2016 [91]

\section{Conclusions}

THA is a rare congenital disorder affecting the thyroid gland. The awareness and understanding of this condition amongst doctors remain poor. Although there is a familial link, it largely remains sporadic. Females are reported to have a higher incidence of THA, like it is with other thyroid disorders. Most cases are diagnosed incidentally in euthyroid patients. THA may be associated with different pathologies including Graves' disease, Hashimoto's thyroiditis, etc. THA also adds to the cost and requirement for lifelong thyroid hormone replacement in those that have had thyroidectomies to remove a diseased thyroid tissue if required. Pre-operative diagnosis and awareness will certainly help healthcare workers and patients make informed decisions.

\section{Additional Information}

\section{Disclosures}

Conflicts of interest: In compliance with the ICMJE uniform disclosure form, all authors declare the following: Payment/services info: All authors have declared that no financial support was received from any organization for the submitted work. Financial relationships: All authors have declared that they have no financial relationships at present or within the previous three years with any organizations that might have an interest in the submitted work. Other relationships: All authors have declared that there are no other relationships or activities that could appear to have influenced the submitted work.

\section{References}


1. Szczepanek-Parulska E, Zybek-Kocik A, Wartofsky L, Ruchala M: Thyroid hemiagenesis: incidence, clinical significance, and genetic background. J Clin Endocrinol Metab. 2017, 102:3124-37. 10.1210/jc.2017-00784

2. Ferrari CC, Lorenz K, Dionigi G, Dralle H: Surgical strategy for primary hyperparathyreoidism with thyroid hemiagenesis. Langenbecks Arch Surg. 2014, 399:1077-81. 10.1007/s00423-014-1228-0

3. Mikosch P, Weixlbaumer V, Irrgang M, Aistleitner A, Trifina-Mikosch E: Hemiagenesis of the thyroid gland detected by coincidence-what is the clinical relevance? : Case report and review of the literature. Wien Med Wochenschr. 2020, 170:403-9. 10.1007/s10354-020-00783-w

4. Sereke SG, Oriekot A, Bongomin F: Thyroid hemiagenesis with a TI-RADS 2 nodule in the contralateral lobe . Thyroid Res. 2021, 14:10. 10.1186/s13044-021-00101-5

5. Maiorana R, Carta A, Floriddia G, et al.: Thyroid hemiagenesis: prevalence in normal children and effect on thyroid function. J Clin Endocrinol Metab. 2003, 88:1534-6. 10.1210/jc.2002-021574

6. Verma A, Bhartiya SK, Basu SP, Shukla VK, Shukla RC: Congenital thyroid hemiagenesis with thyroid nodules-Role of TI-RADS to prevent long term thyroid replacement therapy. Int J Surg Case Rep. 2016, 27:59-62. 10.1016/j.ijscr.2016.07.055

7. Quain R, Wheatstone C: The cyclopaedia of anatomy and physiology. Todd RB (ed): Sherwood, Gilbert, \& Piper, London; 1836.

8. Yang YS, Hong KH: Case of thyroid hemiagenesis and ectopic lingual thyroid presenting as goitre . J Laryngol Otol. 2008, 122:e17. 10.1017/S0022215108003095

9. Sato H, Tsukahara K, Motohashi R, Wakiya M, Serizawa H, Kurata A: Thyroid carcinoma on the side of the absent lobe in a patient with thyroid hemiagenesis. Case Rep Otolaryngol. 2017, 2017:4592783. $10.1155 / 2017 / 4592783$

10. Ayaz ÜY, Ayaz S, Döğen ME, Api A: Ultrasonographic and scintigraphic findings of thyroid hemiagenesis in a child: report of a rare male case. Case Rep Radiol. 2015, 2015:917504. 10.1155/2015/917504

11. Borges MF, Sedassari NA, Sedassari AA, Souza LR, Ferreira BP, Lara BH, Palhares HM: Timing of thyroid ultrasonography in the etiological investigation of congenital hypothyroidism. Arch Endocrinol Metab. 2017, 61:432-7. 10.1590/2359-3997000000239

12. Hashemipour M, Ghasemi M, Hovsepian S, et al.: Etiology of congenital hypothyroidism in Isfahan: Does it different?. Adv Biomed Res. 2014, 3:21. 10.4103/2277-9175.124658

13. Shabana W, Delange F, Freson M, Osteaux M, De Schepper J: Prevalence of thyroid hemiagenesis: ultrasound screening in normal children. Eur J Pediatr. 2000, 159:456-8. 10.1007/s004310051307

14. Gursoy A, Anil C, Unal AD, Demirer AN, Tutuncu NB, Erdogan MF: Clinical and epidemiological characteristics of thyroid hemiagenesis: ultrasound screening in patients with thyroid disease and normal population. Endocrine. 2008, 33:338-41. 10.1007/s12020-008-9095-5

15. Korpal-Szczyrska M, Kosiak W, Swieton D: Prevalence of thyroid hemiagenesis in an asymptomatic schoolchildren population. Thyroid. 2008, 18:637-9. 10.1089/thy.2007.0408

16. Mikosch P, Gallowitsch HJ, Kresnik E, Molnar M, Gomez I, Lind P: Thyroid hemiagenesis in an endemic goiter area diagnosed by ultrasonography: report of sixteen patients. Thyroid. 1999, 9:1075-84. 10.1089/thy.1999.9.1075

17. Ruchala M, Szczepanek E, Szaflarski W, et al.: Increased risk of thyroid pathology in patients with thyroid hemiagenesis: results of a large cohort case-control study. Eur J Endocrinol. 2010, 162:153-60. 10.1530/EJE09-0590

18. Karabay N, Comlekci A, Canda MS, Bayraktar F, Degirmenci B: Thyroid hemiagenesis with multinodular goiter: a case report and review of the literature. Endocr J. 2003, 50:409-13. 10.1507/endocrj.50.409

19. Melnick JC, Stemkowski PE: Thyroid hemiagenesis (hockey stick sign): a review of the world literature and a report of four cases. J Clin Endocrinol Metab. 1981, 52:247-51. 10.1210/jcem-52-2-247

20. Suzuki S, Midorikawa S, Matsuzuka T, et al.: Prevalence and characterization of thyroid hemiagenesis in Japan: The Fukushima Health Management Survey. Thyroid. 2017, 27:1011-6. 10.1089/thy.2016.0662

21. Mohebati A, Shaha AR: Anatomy of thyroid and parathyroid glands and neurovascular relations . Clin Anat. 2012, 25:19-31. 10.1002/ca.21220

22. Organ GM, Organ CH Jr: Thyroid gland and surgery of the thyroglossal duct: exercise in applied embryology . World J Surg. 2000, 24:886-90. 10.1007/s002680010172

23. Policeni BA, Smoker WR, Reede DL: Anatomy and embryology of the thyroid and parathyroid glands . Semin Ultrasound CT MR. 2012, 33:104-14. 10.1053/j.sult.2011.12.005

24. Arrangoiz R, Cordera F, Caba D, Muñoz M, Moreno E, de León EL: Comprehensive review of thyroid embryology, anatomy, histology, and physiology for surgeons. Int J Otolaryngol Head Amp Neck Surg. 2018, 7:160-88. 10.4236/ijohns.2018.74019

25. Faulkner J, Varadharajan K, Choudhury N: A UK reported case of Graves' disease with thyroid hemiagenesis . BMJ Case Rep. 2019, 12:10.1136/bcr-2018-228094

26. Campennì A, Giovinazzo S, Curtò L, Giordano E, Trovato M, Ruggeri RM, Baldari S: Thyroid hemiagenesis, Graves' disease and differentiated thyroid cancer: a very rare association: case report and review of literature. Hormones (Athens). 2015, 14:451-8. 10.14310/horm.2002.1606

27. Szczepanek E, Ruchala M, Szaflarski W, et al.: FOXE1 polyalanine tract length polymorphism in patients with thyroid hemiagenesis and subjects with normal thyroid. Horm Res Paediatr. 2011, 75:329-34. $10.1159 / 000322874$

28. Macchia PE, Lapi P, Krude H, et al.: PAX8 mutations associated with congenital hypothyroidism caused by thyroid dysgenesis. Nat Genet. 1998, 19:83-6. 10.1038/ng0598-83

29. Srichomkwun P, Admoni O, Refetoff S, de Vries L: A novel mutation (S54C) of the PAX8 gene in a family with congenital hypothyroidism and a high proportion of affected individuals. Horm Res Paediatr. 2016, 86:137-42. 10.1159/000445891

30. Szczepanek-Parulska E, Budny B, Borowczyk M, Zawadzka K, Sztromwasser P, Ruchała M: Compound heterozygous GLI3 variants in siblings with thyroid hemiagenesis. Endocrine. 2021, 71:514-9. 10.1007/s12020-020-02422-1

31. Budny B, Szczepanek-Parulska E, Zemojtel T, et al.: Mutations in proteasome-related genes are associated with thyroid hemiagenesis. Endocrine. 2017, 56:279-85. 10.1007/s12020-017-1287-4 
32. Olivieri A, Stazi MA, Mastroiacovo P, et al.: A population-based study on the frequency of additional congenital malformations in infants with congenital hypothyroidism: data from the Italian Registry for Congenital Hypothyroidism (1991-1998). J Clin Endocrinol Metab. 2002, 87:557-62. 10.1210/jcem.87.2.8235

33. Predmore JM, Wang P, Davis F, et al.: Ubiquitin proteasome dysfunction in human hypertrophic and dilated cardiomyopathies. Circulation. 2010, 121:997-1004. 10.1161/CIRCULATIONAHA.109.904557

34. Supakul N, Delaney LR, Siddiqui AR, Jennings SG, Eugster EA, Karmazyn B: Ultrasound for primary imaging of congenital hypothyroidism. AJR Am J Roentgenol. 2012, 199:W360-6. 10.2214/AJR.11.7905

35. Berker D, Ozuguz U, Isik S, Aydin Y, Ates Tutuncu Y, Akbaba G, Guler S: A report of ten patients with thyroid hemiagenesis: ultrasound screening in patients with thyroid disease. Swiss Med Wkly. 2010, 140:118-21.

36. Gurleyik G, Gurleyik E: Thyroid hemiagenesis associated with hyperthyroidism. Case Rep Otolaryngol. 2015, 2015:829712. 10.1155/2015/829712

37. Haymart MR, Repplinger DJ, Leverson GE, Elson DF, Sippel RS, Jaume JC, Chen H: Higher serum thyroid stimulating hormone level in thyroid nodule patients is associated with greater risks of differentiated thyroid cancer and advanced tumor stage. J Clin Endocrinol Metab. 2008, 93:809-14. 10.1210/jc.2007-2215

38. Szczepanek-Parulska E, Zybek-Kocik A, Woliński K, Czarnocka B, Ruchała M: Does TSH trigger the antithyroid autoimmune processes? Observation on a large cohort of naive patients with thyroid hemiagenesis. Arch Immunol Ther Exp (Warsz). 2016, 64:331-8. 10.1007/s00005-016-0393-y

39. Flynn JC, Gilbert JA, Meroueh C, Snower DP, David CS, Kong YC, Banga JP: Chronic exposure in vivo to thyrotropin receptor stimulating monoclonal antibodies sustains high thyroxine levels and thyroid hyperplasia in thyroid autoimmunity-prone HLA-DRB1*0301 transgenic mice. Immunology. 2007, 122:2617. 10.1111/j.1365-2567.2007.02635.x

40. Kocakusak A, Akinci M, Arikan S, Sunar H, Yucel AF, Senturk O: Left thyroid lobe hemiagenesis with hyperthyroidism: report of a case. Surg Today. 2004, 34:437-9. 10.1007/s00595-003-2726-9

41. Mortimer PS, Tomlinson IW, Rosenthal FD: Hemiaplasia of the thyroid with thyrotoxicosis . J Clin Endocrinol Metab. 1981, 52:152-5. 10.1210/jcem-52-1-152

42. Meringolo D, Campi I, Costante G: Severe Graves' Orbitopathy occurring in a patient with thyroid hemiagenesis. Endocrine. 2018, 62:490-1. 10.1007/s12020-018-1662-9

43. Wang M, Hou L, Chen M, Ren L, Tang P, Zhang Y, Jiang J: Thyroid hemiagenesis and Hashimoto's thyroditisdiagnostic and treatment pitfalls. World J Surg Oncol. 2017, 15:182. 10.1186/s12957-017-1250-0

44. Sari O, Ciftçi I, Törü M, Erbaş B: Thyroid hemiagenesis. Clin Nucl Med. 2000, 25:766-8. 10.1097/00003072200010000-00002

45. Rossi ED, Pantanowitz L, Hornick JL: A worldwide journey of thyroid cancer incidence centred on tumour histology. Lancet Diabetes Endocrinol. 2021, 9:193-4. 10.1016/S2213-8587(21)00049-8

46. Bray F, Ferlay J, Soerjomataram I, Siegel RL, Torre LA, Jemal A: Global cancer statistics 2018: GLOBOCAN estimates of incidence and mortality worldwide for 36 cancers in 185 countries. CA Cancer J Clin. 2018, 68:394-424. 10.3322/caac.21492

47. Saad Abdalla Al-Zawi A: The Oncotype DX recurrence score impact on the management of ER-Positive, HER2-negative,node-negative breast cancer . Medical Research Journal. 2021, 6(3):211-6. 10.5603/MRJ.a2021.0041

48. Huang SM, Chen HD, Wen TY, Kun MS: Right thyroid hemiagenesis associated with papillary thyroid cancer and an ectopic prelaryngeal thyroid: a case report. J Formos Med Assoc. 2002, 101:368-71.

49. Pizzini AM, Papi G, Corrado S, Carani C, Roti E: Thyroid hemiagenesis and incidentally discovered papillary thyroid cancer: case report and review of the literature. J Endocrinol Invest. 2005, 28:66-71. 10.1007/BF03345532

50. Ammaturo C, Cerrato C, Duraccio S, et al.: Thyroid hemiagenesis associated with Flajani's disease and papillary carcinoma. A case report (Article in Italian). Chir Ital. 2007, 59:263-7.

51. Canani FB, Dall'Olio D, Chiarini V, Casadei GP, Papini E: Papillary carcinoma of a thyroglossal duct cyst in a patient with thyroid hemiagenesis: effectiveness of conservative surgical treatment. Endocr Pract. 2008, 14:465-9. 10.4158/EP.14.4.465

52. Lee YS, Yun JS, Jeong JJ, Nam KH, Chung WY, Park CS: Thyroid hemiagenesis associated with thyroid adenomatous hyperplasia and papillary thyroid carcinoma. Thyroid. 2008, 18:381-2. 10.1089/thy.2007.0281

53. Karatağ GY, Albayrak ZK, Önay HK, Karatağ O, Peker Ö: Coexistence of thyroid hemiagenesis, nodular goitre and papillary carcinoma. Kulak Burun Bogaz Ihtis Derg. 2013, 23:115-8. 10.5606/kbbihtisas.2013.60590

54. Vayisoglu Y, Ozcan C, Gen R, Eti CM, Sut H, Gorur K: Thyroid isthmus agenesis associated with thyroid papillary carcinoma. [corrected]. J Craniofac Surg. 2013, 24:e428-9. 10.1097/SCS.0b013e3182942d5c

55. Wang I, Gao L, Song C: Thyroid hemiagenesis associated with medullary or papillary carcinoma: report of cases. Head Neck. 2014, 36:E106-11. 10.1002/hed.23501

56. Sakorafas GH, Katseni KK, Thanos D, Nasikas D, Goutis G, Deskoulidi P: Thyroid cancer in a patient with congenital thyroid hemiagenesis. Int J Endocr Oncol. 2015, 2:109-10. 10.2217/ije.15.3

57. Rajbhandari P, Shrestha BL, Dhakal A, Amatya RC: Thyroid isthmus agenesis in a patient with papillary carcinoma of thyroid. Kathmandu Univ Med J (KUMJ). 2016, 14:373-5.

58. Ugur K, Sevgi K, Tugrul K, Sengul D: Agenesis of isthmus of thyroid gland in the presence of ectopic thyroid tissue associated with papillary carcinoma. J Coll Physicians Surg Pak. 2019, 29:75-7. 10.29271/jcpsp.2019.01.75

59. Gandla S, Halkud R, Siddappa KT, Murthy SP, Ray SL, Samriddhi, Greeshma P: Thyroid hemiagenesis and papillary carcinoma: a rare association. Indian J Surg Oncol. 2020, 11:84-6. 10.1007/s13193-020-01068-9

60. Alqahtani SM, Alanesi S, Alalawi Y: Thyroid hemiagenesis with primary hyperparathyroidism or papillary thyroid carcinoma: A report of two cases and literature review. Clin Case Rep. 2021, 9:1615-20. 10.1002/ccr3.3856

61. Maganini RJ, Narendran K: Hyperparathyroidism in a patient with thyroid hemiagenesis . IMJ Ill Med J. 1977, 151:368-70.

62. Sakurai K, Amano S, Enomoto K, Matsuo S, Kitajima A: Primary hyperparathyroidism with thyroid hemiagenesis. Asian J Surg. 2007, 30:151-3. 10.1016/S1015-9584(09)60151-2 
63. Mydlarz WK, Zhang K, Micchelli ST, Kim M, Tufano RP: Ipsilateral double parathyroid adenoma and thyroid hemiagenesis. ORL J Otorhinolaryngol Relat Spec. 2010, 72:272-4. 10.1159/000312707

64. Isreb S, Alem F, Smith D: Left thyroid hemiagenesis in a patient with primary hyperparathyroidism . BMJ Case Rep. 2010, 2010:10.1136/bcr.03.2010.2864

65. Kroeker TR, Stancoven KM, Preskitt JT: Parathyroid adenoma on the ipsilateral side of thyroid hemiagenesis. Proc (Bayl Univ Med Cent). 2011, 24:92-3. 10.1080/08998280.2011.11928690

66. Oruci M, Ito Y, Buta M, Radisavljevic Z, Pupic G, Djurisic I, Dzodic R: Right thyroid hemiagenesis with adenoma and hyperplasia of parathyroid glands -case report. BMC Endocr Disord. 2012, 12:29. 10.1186/1472-6823-12-29

67. Eroglu M, Ozkul F, Barutcu EC, et al.: Severe hyperparathyroidism in patient with right thyroid hemiagenesis. JPMA J Pak Med Assoc. 2015, 65:1022-3.

68. Matsumura LK, Russo EM, Dib SA, Maciel RM, Chacra AR: Hemiagenesis of the thyroid gland and T3 hyperthyroidism. Postgrad Med J. 1982, 58:244-6. 10.1136/pgmj.58.678.244

69. Bando Y, Nagai Y, Ushiogi Y, Toya D, Tanaka N, Fujisawa M: Development of Graves' hyperthyroidism from primary hypothyroidism in a case of thyroid hemiagenesis. Thyroid. 1999, 9:183-7. 10.1089/thy.1999.9.183

70. Ruchała M, Szczepanek E, Skiba A, Czepczyński R, Sowiński J: Graves' hyperthyroidism following primary hypothyroidism due to Hashimoto's thyroiditis in a case of thyroid hemiagenesis: case report. Neuro Endocrinol Lett. 2008, 29:55-8.

71. Lee IT, Sheu WH, Lin SY: Familial form of thyroid dysgenesis: report of thyroid hemiagenesis with accompanying Graves' disease in a woman whose daughter has thyroid agenesis. Horm Res. 2003, 59:47-9. 10.1159/000067938

72. Baldini M, Orsatti A, Cantalamessa L: A singular case of Graves' disease in congenital thyroid hemiagenesis . Horm Res. 2005, 63:107-10. 10.1159/000084568

73. Nebesio TD, Eugster EA: Unusual thyroid constellation in Down syndrome: congenital hypothyroidism, Graves' disease, and hemiagenesis in the same child. J Pediatr Endocrinol Metab. 2009, 22:263-8. 10.1515/jpem.2009.22.3.263

74. Cakir M, Gonen S, Dikbas O, Ozturk B: Thyroid hemiagenesis with Graves' disease, Graves' ophthalmopathy and multinodular goiter. Intern Med. 2009, 48:1047-9. 10.2169/internalmedicine.48.1984

75. Kebapçilar L, Akinci B, Demir T, Bayraktar F, Yeşil S: Hypercalcemia due to Graves' disease in a patient with thyroid hemiagenesis. Kulak Burun Bogaz Ihtis Derg. 2009, 19:159-62.

76. Shechner C, Kraiem Z, Zuckerman E, Dickstein G: Toxic Graves' disease with thyroid hemiagenesis: diagnosis using thyroid-stimulating immunoglobulin measurements. Thyroid. 1992, 2:133-5. 10.1089/thy.1992.2.133

77. Ozaki O, Ito K, Mimura T, Sugino K, Kitamura Y, Iwabuchi H, Kawano M: Hemiaplasia of the thyroid associated with Graves' disease: report of three cases and a review of the literature. Surg Today. 1994, 24:164-9. 10.1007/BF02473402

78. Véliz J, Pineda G: Thyroid hemiagenesis associated with Basedow-Graves disease. Report of a case (Article in Spanish). Rev Med Chil. 2000, 128:896-8.

79. Hervás Benito I, Vera Espallardo F, Rivas Sánchez A, et al.: Association of thyroid hemiagenesis and Graves disease (Article in Spanish). Rev Esp Med Nucl. 2001, 20:116-9. 10.1016/s0212-6982(01)71937-4

80. Zangeneh F, Miller JL, Intenzo CM: Thyroid gland hemiagenesis with Graves' disease. Thyroid. 2001, 11:603. 10.1089/105072501750302930

81. Ozgen AG, Saygili F, Kabalak T: Thyroid hemiagenesis associated with Graves' disease and Graves' ophthalmopathy: case report. Thyroid. 2004, 14:75-7. 10.1089/105072504322783885

82. Serdengeçti M, Ayan A, Sari O: Thyroid hemiagenesis and Graves' disease in a child . Clin Nucl Med. 2009, 34:884-5. 10.1097/RLU.0b013e3181bed120

83. Philip R, Ashokan A, Philip R, Keshavan C: Graves' disease with thyroid hemiagenesis: a rare abnormality with rarer presentation. Indian J Nucl Med. 2014, 29:124-5. 10.4103/0972-3919.130321

84. Cansu GB, Taşkıran B, Bahçeci T: Thyroid hemiagenesis associated with Graves' disease: a case report and review of the literature. Acta Endocrinol (Buchar). 2017, 13:342-8. 10.4183/aeb.2017.342

85. Sharma R, Mondal A, Popli M, Sahoo M, Malhotra N, Soni S: Hemiagenesis of the thyroid associated with chronic lymphocytic thyroiditis. Clin Nucl Med. 2001, 26:506-8. 10.1097/00003072-200106000-00005

86. Nsame D, Chadli A, Hallab L, El Aziz S, El Ghomari H, Farouqi A: Thyroid hemiagenesis associated with Hashimoto's thyroiditis. Case Rep Endocrinol. 2013, 2013:414506. 10.1155/2013/414506

87. Bosco D, Cammarata A, Cannarella R, Latino R, Lanteri R, Di Cataldo A, Calogero A: Thyroid hemiagenesis associated with multinodular goiter and Hashimoto's thyroiditis. G Chir. 2017, 38:291-4. 10.11138/gchir/2017.38.6.291

88. Vakili R, Mazlouman SJ: Dyshormonogenic hypothyroidism with normal neurological development, unexplained short stature and facial anomalies in three siblings. Clin Dysmorphol. 2003, 12:21-7. 10.1097/00019605-200301000-00004

89. Gursoy A, Sahin M, Ertugrul DT, Berberoglu Z, Sezgin A, Tutuncu NB, Demirag NG: Familial dilated cardiomyopathy hypergonadotrophic hypogonadism associated with thyroid hemiagenesis. Am J Med Genet A. 2006, 140:895-6. 10.1002/ajmg.a.31161

90. Ng TT, Soon DS, Mahanta V: A tale of two anomalies: fourth branchial cleft cyst with thyroid hemiagenesis . ANZ J Surg. 2018, 88:E677-8. 10.1111/ans.13637

91. Ammar FA, Al-Badri MR, Zantout MS, Azar ST: Thyroid hemiagenesis coexisting with brain cavernoma and pituitary Rathke's cleft cyst. J Postgrad Med. 2016, 62:135-6. 10.4103/0022-3859.174161 